\title{
Investigating the Strategies Used in Translation of Ironies in English Short Stories translated into Persian
}

\author{
Mana Alahmad \\ Islamic Azad University, Central Tehran Faculty of Foreign Languages, Iran \\ mana.alahmad60@gmail.com
}

\begin{abstract}
This study attempted to investigate the strategies which were used by Persian translators in translation of ironies. Translating irony has always been challenging as it relates to each nation culture and language background. So, special strategies are needed to guide the translators to find suitable equivalences for the ironies within any second language. In this research, strategies for translating two types of ironies i.e. verbal and situational were investigated via short stories. Eight short stories of Ernest Hemingway were chosen as the English texts. For each story two Persian versions were selected.Baker (1992) model of translation strategies was considered as the framework. The result of the total frequency count of the strategies adopted in translating the ironies by the translators'indicated that the most common strategies which used by these translators to translate English verbal and situational ironies into Persian were cultural equivalences and general or neutral equivalences for English words and phrases.The findings are of help to translators, translation trainers and readers among all interested parties.
\end{abstract}

Keywords: Irony; translation; strategy; equivalence; source text; target text

\section{Introduction}

This study attempted to adopt Baker (1992) model of strategies for translation of idioms, here ironies. A corpus including eight English short stories of Earnest Hemingwayalong with their Persian translations selected. Translation process, either oral or written, has always been challenging, cumbersome and debatable (Newmark, 1991 andHatim and Munday, 2004). There have been debates over the concept of translation for many yearsfrom different perspectives. Linguists and experts like Nida (1982), Newmark (1988) and Baker (1992) believe that translation is something beyond finding equivalences of source language in the target language. Further, whatever translation is, it should be able to transfer the source language's both concept and style into the target language. As such, besides the linguistic difficulty, lack of sameness between languages (Bassnett, 2007), of translation, the cultural and national traditions add to this difficulty; that is to say the way it is interpreted and meaning transferred. Therefore, an amalgamation of linguistic and cultural processes- cultural knowledge and cultural difference - causes the languages vague or ambiguous for other people across the world.

Since translation is a cross cultural process, its building blocks i.e., words and phrases like colloquial terms, among them "irony" are so heavily and exclusively grounded in one culture that they are almost impossible to be translated and interpreted cross culturally. Irony is no exception. It is well known that "irony" is one of the most subtle devices (Reyes and Rosso, 2014) used to, in a refined way, deny what is literally said. Further, it is the adoption of a point of view 'above' a context, allowing us to view the context from 'high' (Colebrook, 2004). Fasold (1977) defined irony as saying something other than what is meant and saying the opposite of what is meant. According to Ghazala (2007), the delicacy and subtlety of irony, especially when it is culture-based, makes it hard to tackle in translation. Yet it is not an inseparable problem of translation. Translating, understanding and transferring colloquial English, especially irony is very demanding, and if done incorrectly, it will cause misunderstanding and make the text and message nonsense. Therefore, due to subtlety, 
delicacy, ambiguity and culture specificity nature of ironies and the difficulties they cause, this study tried to reduce the ironies strange cross cultural load by adopting and investigating proper strategies in Persian using short stories. The model of strategies for translation of ironies in the current study was based on Baker (1992). This study results will pave the way for translators, readers and trainers to interpret ironies better, teach them efficiently and get across the messages easily.

Based on the explanation above the question arised is what strategies are most commonly used by Iranian translators to translate ironies in short stories from English to Persian according to Baker's (1992) model?

\section{Literature Review}

This study tried to adopt Baker (1992) model of ironies strategies to be applied in the Persian translation of Hemingway short stories. That is to say, this study at its best embarked on exploration of short stories to see what strategies were more efficient in translation of ironies in Persian.

\subsection{Irony}

Perrine (1974) claimed that irony is a term with a range of meanings, all of them involving some sort of discrepancy or incongruity. It shouldn't be confused with sarcasm which is simply language designed to cause pain. The story writer uses irony to suggest the complexity of experience, to furnish indirectly an evaluation of his material, and at the same time to achieve compression. Colebrook (2005) believes despite its widely complexity, irony has a frequent and common definition: saying what is contrary to what is meant. According to Abrams (1999) in modern cases the "irony" is used to hide the fact, not to deceive, but to achieve special rhetorical or artistic effects. There are nine types of ironies in one classification according to Abrams (1999): verbal irony, structural irony, stable irony, unstable irony, Socratic irony, dramatic irony, tragic irony, cosmic irony and romantic irony.

\subsection{Irony, metaphor, humor and satire}

According to Hutcheon, (1994) the difference between irony and metaphor is that other figures of speech make a comparison, contrast or likeness while irony invokes an absent or hidden sense. Even in a complex metaphor such as 'the mind is a mirror' we may be unclear as to just what comparison is being made, but we are nevertheless given some term other than the literal. If we say 'the mind is a computer', we may be referring to its speed, materiality, complexity, structure, simplicity or memory. But in irony we are given one term that is negated, so that when Socrates refers to Thrasymachus as clever, and we assume this is ironic, we have no other term to replace 'clever' with (Colebrook, 2005).

Irony, according to Deleuze (1994), is a tendency in thinking, a tendency to not rest with the world in all its flux of differences, a tendency to posit some ultimate point of view beyond difference. The problem with irony, from Deleuze's point of view, is its elimination of all difference-its inability to admit what is beyond its point of view. And it is this ironic ascent that has dominated Western thinking: Classical irony acts as the instance which assures the coextensiveness of being and of the individual within the world of representation' (Colebrook, 2005, p. 134-135). Deleuze (1994) frequently refers to humor, and occasionally satire, as a tendency opposed to irony (Deleuze, 1994, 5). Instead of thinking in terms of the concept as a 
law that governs what we say, humour and satire focus on the bodies, particularities, noises and disruptions that are in excess of the system and law of speech. Humour beyond irony, or what Deleuze (1994) refers to as superior irony, is the art of surfaces, the art of thinking the noise, sensations, affects andsensible singularities from which bodies are composed, bodies that canthen have relations: 'Humour is the art of the surface, which is opposedto the old irony, the art of depths and heights' (Colebrook, 2005, p. 132).

Irony focuses on the subject, on the consciousness or power that lies above and beyond any specific character or utterance. Satire focuses on man: the human animal that may elevate himself through moral language but who, at bottom, is ultimately nothing more than a collection of desires and interests, a living and dynamic body rather than a timeless soul (Colebrook, 2005, p. 139).Satire recognizes the lowly animal being behind all our ideas of selfcreation. Satire is immanently historical; looking at the ways in which ideas of 'man' have been produced from the flow of life. (Colebrook, 2005, p. 141).

\subsection{Difficulties of idioms translation}

- An idiom or fixed expression may have no equivalent in the target language.

- An idiom or fixed expression may have a similar counterpart in the target language, but its context of use may be different.

- An idiom may be used in the source text in both its literal and idiomatic senses at the same time.

- The very convention of using idioms in written discourse, the contexts in which they can be used, and their frequency of use may be different in the source and target languages. (Baker, 1992, 68-70).

\subsection{Strategies of idioms translation}

Totally the model which is used in this study can be summarized to five strategies:

- Using a more general/neutral word or phrase/idiom.

- Using a cultural substitution for words/similar meaning with different form for idioms.

- Using a loan word or phrase.

- Explaining the word in a phrase/translating the idiom.

- Omitting the word, phrase or idiom (Baker, 1992, p. 72-77).

\section{Methodology}

The present study was a corpus-based research which focused on eight of the Hemingway's short stories and their Persian translated versions. It investigated the common strategies, according to the model proposed by Baker (1992) used by Iranian translators to translate verbal and situational ironies in these short stories into Persian. This research was conducted to find the strategies which are used by translators to find Persian equivalences for English ironies in some of Hemingway's short stories according to what Baker (1992) presented and is considered as her model.In this chapter the corpora, procedure and design of the study were discussed. 


\subsection{Corpus}

To fulfill the purpose of the research the researcher choseeight short stories by Ernest Hemingway and two Persian translations for each ofthe stories which means sixteentranslations of the stories overall.

\subsection{Procedure}

To conduct the present study the researcher first studied the English stories and detected the verbal and situational ironies.Secondly, to validate the job, four university professors who were experts in English literature studied the stories and the ironies identified by the researcher and certified their correctness as being ironies in these stories. Thirdly, the researcher studied the Persian versions of the stories and compared them with each other and the English ones. Then, she found the strategies used by each translator for translating the ironies according to Baker's model. Finally, she presented the most common strategies which were used by these translators.

\section{Results and Discussion}

The examples were chosen as verbal and situational ironies. The only point that has to be mentioned here is that these sentences may not seem ironic at first glance but as all of the consultants mentioned earlier agreed, they should be considered in the context and within the context they become ironic. So, these ironies were investigated based on their meanings in the short stories. To answer the designed research question, model of translation strategies of Baker (1992)adopted. The strategies selected by translators to translate ironies were first determined and tallied and the results obtained were presented in table form for each of the four translations in terms of frequencies and percentages. The selected strategies were put in order of preferences. For ease and continence, the strategies were abbreviated in terms of S1 to S5 in this study. As has been said the findings were tabulated, and the content of every table was accompanied by some illustration. To add more, next to giving frequencies and percentages, the number of ironies, that is to say, verbal and situational found in the short stories presented below.

Table 1. Baker (1992) Model of strategies for the translation of idioms

\begin{tabular}{|l|c|}
\hline \multicolumn{1}{|c|}{ Strategies } & $\begin{array}{c}\text { Labels and order } \\
\text { of strategies }\end{array}$ \\
\hline 1. Using a more general/neutral word or phrase/idiom. & (S1) \\
\hline $\begin{array}{l}\text { 2. Using a cultural substitution for words/similar meaning } \\
\text { with different form for idioms. }\end{array}$ & (S2) \\
\hline 3. Using a loan word or phrase. & (S3) \\
\hline 4. Explaining the word in a phrase/translating the idiom. & (S4) \\
\hline 5. Omitting the word, phrase or idiom. & (S5) \\
\hline
\end{tabular}

Table indicated the 5 strategies (S) which tested in this study. Every strategy for ease and convenience abbreviated as S. these strategies were ordered according to the degree of use in translation of ironies in this study.

Table 2. The number of verbal and situational ironies in the English stories 8 verbal ironies and 1 situational irony in "The Killers" 7 verbal ironies in "Hills Like White Elephants" 5 verbal ironies in "Fifty Grand" 


\begin{tabular}{|l|}
\hline 1 verbal irony and 2 situational ironies in "The Snows of Kilimanjaro" \\
\hline 1 verbal irony and 4 situational ironies in "Cat in the Rain" \\
\hline 1 verbal irony and 4 situational ironies in "A Clean Well-Lighted Place" \\
\hline 3 situational ironies in "Indian Camp" \\
\hline $\begin{array}{l}2 \text { verbal ironies and } 2 \text { situational ironies in "The Short Happy Life of Francis Macomber" } \\
\text { which means } 25 \text { verbal ironies and } 16 \text { situational ironies which make } 41 \text { ironies totally. }\end{array}$ \\
\hline
\end{tabular}

Table 2 presented the number of verbal and situational ironies (two important groups) which were probed through this study. It is clear that in 5 stories cases of ironies found.

Table 3. Frequency and Percentage of Strategies Used in Persian Translations

\begin{tabular}{|l|l|l|}
\hline \multicolumn{1}{|c|}{ Strategies } & Frequency & Percentage \\
\hline $\begin{array}{l}\text { Using a more general/neutral word or } \\
\text { phrase/idiom: }\end{array}$ & 30 & $20 \%$ \\
\hline $\begin{array}{l}\text { Using a cultural substitution for words/similar } \\
\text { meaning with different form for idioms: }\end{array}$ & 109 & $73 \%$ \\
\hline Using a loan word or phrase: & 2 & $1 \%$ \\
\hline $\begin{array}{l}\text { Explaining the word in a phrase/translating the } \\
\text { idiom: }\end{array}$ & 0 & $0 \%$ \\
\hline Omitting the word, phrase or idiom: & 9 & $6 \%$ \\
\hline
\end{tabular}

If we want to summarize the above-mentioned used strategies we have to put it in this way according to table 3:S1 has been used 30times tantamount with $20 \%$. Further, S2 was used 109 times for translation of ironies, that is to say something about $73 \%$.For example:

Table 4. Examples of Strategies and the Sentences

\begin{tabular}{|c|c|c|c|}
\hline English Ironies & $\begin{array}{l}\text { Type of } \\
\text { Irony }\end{array}$ & Persian Translations & Number \\
\hline This is a hot town. & verbal & جه شهر لجن درمالى. & 2 \\
\hline Just a bright boy. & verbal & كى ميحه تو زبل نيستى! & 1 \\
\hline Oh, he's a thinker! & verbal & آره ، بلند نظره. & 1 \\
\hline $\begin{array}{l}\text { You ought to go to the } \\
\text { movies more. The movies } \\
\text { are fine for a bright boy like } \\
\text { you. }\end{array}$ & verbal & 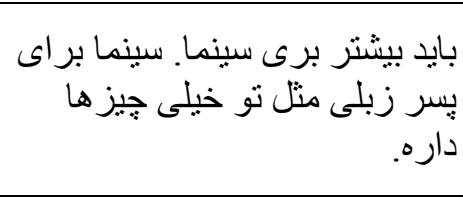 & 2,1 \\
\hline $\begin{array}{l}\text { You'd make some girl a } \\
\text { nice wife, bright boy. }\end{array}$ & verbal & 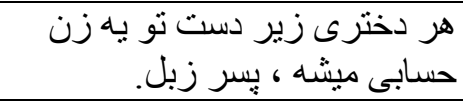 & 2 \\
\hline
\end{tabular}

In addition, the S3 only used 2 times or 1\% and S5 have been used 9 times and $6 \%$ percent.Therefore, the majority of the ironies studied in these corpora were translated through the second strategy and first strategies (in Baker's model), that is using a cultural substitution for words and phrases and Using a more general/neutral word or phrase/idiom. The least frequently used strategy has been explaining words in phrases and using a loan word or phrase.

\section{Conclusion}

In this research it is found out that using a cultural substitution for words has been the most common strategy and explaining the words in phrases has been the least popular strategy 
used by translators. Further, it can be said that these Iranian translators preferred to use the words which are known for Iranian readers in their translations. As such, a plausible reason for this choice may be that they find this strategy appropriate in rendering the ironic meaning of the SL ironies in a culturally understandable manner. The main advantage of using this strategy was that it gives the reader a concept with which s/he canidentify something familiar and appealing. On an individual level, thetranslator's decision to use this strategy largely depended on (a) how much license is given to him/ her by those who commission the translation and (b) the purpose of the translation. On a more general level, the decisions will alsoreflect, to some extent, the norms of translation prevailing in a givencommunity. Linguistic communities vary in the extent to which they toleratestrategies that involve significant departure from the propositional meaningof the text (Baker, 1992, p. 31).

On the other hand, explaining the words which do not have equivalents in Persian is not common at all, maybe again because it devalues the translation and makes it vague and complicated to understand for the audience. These translators did not use S3 much as well. The reason can be using a loan word is not popular among Iranians and translators prefer to resist them in their works. The most used strategy was strategy "Using a cultural substitution for words/similar meaning with different form for idioms". It shows that Iranian translators use words and phrases which are common in Iranian culture and Persian language. Further, "Using a more general/neutral word or phrase/idiom", "Omitting the word, phrase or idiom" and "Using a loan word or phrase "were mostly used respectively in next levels. It can be concluded that Iranian translators first try their best to find Persian equivalents for the English ironies in texts. Secondly, if they find it problematic to translate the whole sentence or words, they use more general or neutral words or phrases. Thirdly, they omit a part or some parts which are problematic. Finally, they use loan words for the ones which are not possible to be translated into Persian. It must be taken into consideration that Iranian translators do not explain the English words which do not have Persian equivalents in sentences or phrases (S 4). Iranian translators try their best to translate English ironies into Persian based on the cultural factors.

The findings of this research can be useful for translators, especially the amateur ones to know and use the strategies which are more frequent in translating ironies in short stories for Iranian audiences. These strategies may be used in other types of texts and, however; it shows which strategies in translation can attract Iranian readers whose mother tongues are Persian. The same research can be done on more short stories written by other writers. Moreover, the same research can be done on short stories of different genres or different political or literal eras and decades. Further, the same research can be carried out on other types of texts like novels, poems and even on movies. Finally, similar studies can be done by using a questionnaire to find out which translations are more popular with people and what the reasons are.

\section{References}

Alfa Rosyid Abdullah, Herman J. Waluyo, Nugraheni Eko Wardani, (2019). The Value of Social Care Character Education Through Merindu Baginda Nabi. Avialable at: www.bircu-journal.com/index.php/birci

Newmark, P. (1988). A textbook of translation (Vol. 1, p. 988). New York: Prentice hall. Hatim, B., \&Munday, J. (2004). Translation: An advanced resource book. Psychology Press. Reyes, A., \&Rosso, P. (2014). On the difficulty of automatically detecting irony: beyond a simple case of negation. Knowledge and Information Systems, 40(3), 595-614. 
Myers, A. R. (1977). Toward a definition of irony. Studies in language variation: semantics, syntax, phonology, pragmatics, social situations, ethnographic approaches, 171-183.

Ghazala, H. (2007). Touching upon the translation of the style of irony (EnglishArabic). Babel, 53 (1).

Hutcheon, L. (1994). Irony's edge: The theory and politics of irony. Psychology Press.Newmark, P. (1991). About translation (Vol. 74). Multilingual matters.

Deleuze, G. (1994). Difference and repetition. Columbia University Press.

Abrams, M. H. (1999).A glossary of literary terms $\left(7^{\text {th }}\right.$ ed.). Boston: Heinle\&Heinle.

Baker, M. (1992).In other words (a coursebook on translation).NewYork: Routledge.

Bassnett, S. (2007).Translation studies. New York: Routledge.

Colebrook, C. (2004). Irony. London: Routledge.

Hatim, B. and Munday, J. (2004).Translation (an advanced resource book). NewYork: Routledge.

Hemingway, E. (1987). The complete short stories of Ernest Hemingway. New York: Scribner.

Nida, E. and Taber, Ch. (1982). The theory and practice of translation. Leiden: E. J. Brill.

Perrine, L. (1974). Literature (structure, sound, and sense). NewYork: Harcourt Brace Jovanovich, Inc. 